\title{
IRAK4 Inhibitor CA-4948
}

National Cancer Institute

\section{Source}

National Cancer Institute. IRAK4 Inhibitor CA-4948. NCI Thesaurus. Code C148455.

An orally bioavailable, reversible inhibitor of interleukin-1 receptor-associated kinase 4 (IRAK4), with potential antineoplastic, immunomodulating and anti-inflammatory activities. Upon oral administration, CA-4948 targets, binds to, and blocks the kinase activity of IRAK4. This inhibits IRAK4-mediated signaling, prevents the activation of IRAK4-mediated nuclear factor-kappa B (NF-kB) signaling and decreases the expression of inflammatory cytokines and certain pro-survival factors. This inhibits proliferation of IRAK4-overactivated tumor cells, which are found in cells harboring MYD88 activating mutations or those with overactivated toll-like receptor (TLR) pathways. In addition, CA4948 may inhibit inflammation and immune-mediated cell destruction in inflammatory and auto-immune diseases where TLR or interleukin 1 receptor (IL-1R) signaling is overactivated and MYD88 is dysregulated. IRAK4, a serine/threonine-protein kinase that plays a key role in both the TLR and IL-1R signaling pathways, is activated though the adaptor protein MYD88 and links the TLR and IL-1R signaling pathway to the NF-kB pathway. 